\title{
Expert system approach to safety management
}

\author{
P. Baron, P. Brázda, J. Dobránsky \& M. Kočiško \\ The Faculty of Manufacturing Technologies, \\ Technical University of Košice with a seat in Prešov, Slovakia
}

\begin{abstract}
The requirements of the EU framework directives and national legislation demand the implementation of systematic steps within the scope of risk management. The task is therefore to develop devices with an acceptable value of residual risk and to undertake the steps of technical and human risk assessment in existing workplaces. These requests inspired the members of this team to develop an expert system which is able to utilize the selected method of risk assessment as a part of the production documentation preparation carried out by the Computer Aided Production Planning System Sysklass. This solution uses the approach of concurrent engineering where several steps can be undertaken simultaneously during the production process in order to reveal errors which may later result in death, health, system or environmental damage. The properties of the proposed expert system make it suitable for usage in the student training process at our university and in the safety management of smaller and middlesized companies.

Keywords: residual risk, acceptable risk, danger, threat, expert system.
\end{abstract}

\section{Introduction}

Safe work environment is one of the basic rights of employees, guaranteed by the current European and national and legislation. In advanced countries, lack of appropriate management is considered to be the cause of injuries and damage to health, work environment or the equipment. This is confirmed by a large number of fatal and serious work injuries. Official statistics talk about 2.2 million deaths per year worldwide [1]. However, real numbers are even worse. This is mainly caused by the absence of real work accident register in the less developed countries. Several myths are connected with this, for example that a workplace without any reported accidents is never a safe one. Injuries always result from a 
potential danger. It is therefore necessary that employers, in cooperation with their employees, take all the measures that form a part of the real risk management assessment in individual workplaces. It is important to realize that there is no absolute safety and, as relevant statistics show, accidents are mainly caused by irresponsible conduct, violation of work safety procedures and a breach of safety regulations.

European directives on safety and health at work have their legal foundation in the Article 137 of the EU Treaty. The basis of the EU legislation concerning occupational safety and health is formed by the framework directive with a wide range of application and by other specialized directives. These stipulate the minimum requirements and basic principles such as the principle of prevention and risk assessment. They also designate the liabilities of employees and employers. Machine safety is covered by the directive no. 2006/42/ES of 17 May, 2006. It was amended by the directive no. 2009/127/ES which addresses pesticide application equipment. In the Slovak Republic, this directive was implemented by the cabinet decree no. 436/2008, which established the specifications of technical parameters and methods of machinery conformity assessment. Modern approaches to technical preparation of production demand not only that the designed product be foolproof but also that it satisfies all actual specifications of technical, hygiene, ecology and fire safety measures and specifications. The methodology of risk assessment in the process of machine design is established by the technical norm STN EN ISO 14121-1 Machine safety, Risk assessment, Chapter 1: Principles, from 2008 (which overrules the norm EN 1050) and STN ISO 12100-1, 2: Machine safety - Basic terms, general principles of machine design. Chapter 1: Basic terminology, methodology and Chapter 2: Technical principles. Both were adopted in 2004. The adoption of the framework directive no. 89/391/ES, which addresses the procedures for the improvement of occupational safety and health (further SPWH), resulted in the change of many approaches and procedures as well as the philosophy of occupational safety. The basic principle of the new SPWH policy is the duty to assess risks. This principle has gradually been transformed into integrated safety theories and injury free prevention. In fact, these theories have created a new branch of science - riskology [2-5].

\section{Computer aided risk identification, assessment and registration of industrial accident records}

The above mentioned data provided an impulse for the development of a complex system of computer support, which utilizes selected methods of risk identification and assessment as well as the registration of the registered industrial accident rate for the period stipulated by law.

Software applications supporting process of risk assessment in workplaces have recently undergone major development. The application environment BTS product of Be-soft a.s. is a leading product in this area. It integrates the implementation of systems into occupational safety and health protection, fire protection, protection of environment, civil protection and risk assessment. The 
main asset of this system is the possibility of online update of the occupational safety software according to valid directives.

CIRSMA $^{\mathrm{TM}}$ represents a software system of Industrial Safety Integration Company, created for risk analysis and determination of suitable methodology of risk restriction, reflecting the needs of the enterprise environment. This application integrates the system tools of risk identification and elimination in the design phase of the proposed system.

Serious industrial emergencies assessment makes use of the software system ASSESS-RISK, developed by Fluidyn Co. ASSESS-RISK is based on UFTP (Union Francaise d'Industrie Petroliere) methodology and is the result of participant's exercises. The techniques used for risk assessment are based on qualitative methods, semi-quantitative or quantitative criteria. The basic approach is the evaluation of both the level of consequence and the associated level of probability. Here, the consequences and the probabilities are divided into six categories. Different regulations distinguish three levels of risk: lethal, destruction and irreversible. Risks are classified into four types: due to toxic dispersion, overpressure, thermal radiation and missile effects [6].

Other software application, currently used in cooperation with system of quality control, is the EtQ's Environmental Health and Safety (EHS) of ETQ Excellence Through Quality Co. EHS is a flexible software package that guides companies in compliance with ISO 14001, ISO 9000, OHSAS 18001 and similar standards for environmental health and safety management.

The process of risk assessment and control in workplaces can use a wide variety of further commercially available software tools, each having their advantages as well as limitations. Some of these software solutions represent simple risk matrices, other complex algorithms for the determination of residual risk.

Our main aim was the creation of an intelligent tool for the processing of risk assessment and occupational safety in workplaces. In accordance with the concurrent engineering philosophy, its structure was designed in such a way, that the risk assessment process is applied during the phase of product development in cooperation with the systems of computer support of preproduction stages. It also contains the method of risk assessment and determination of work safety for existing workplaces. The system uses inductive and deductive approaches to risk analyses. Integral part of the system is a module for work accident report. Its direct integration into the Computer Aided Production Planning System, this software represents an original software solution among the expert systems of this category.

This expert system was developed with the support of the KEGA grant scheme (Cultural and Educational grant agency of Ministry of Education of Slovak Republic) no. 3/4135/06 - "Creation of electronic educational materials for risk management in production technologies". It incorporates the results and conclusions of a habilitation thesis of one of the authors of this paper as well as the results and conclusions of an undergraduate thesis written at the Department of Production Technologies of the Faculty of Manufacturing Technologies of Technical University of Košice with a seat in Prešov. This system represents a 
custodial tool to the Computer Aided Process Planning system - Sysklass, providing risk assessment results integration to facilitate the integration of the risk assessment results on technological workplaces or, in case of newly designed devices, for its production documentation.

On the basis of the above mentioned reasons, the following methods for identification and assessment were selected:

- Method of combined approach which consist of catalogue sheet method for risk identification and scoring method for risk assessment

- FMEA Method (Failure Mode and Effect Analysis) for the identification of errors and the related risks

- HAZOP Method (Hazard Analysis and Operability Study) for the identification of risks at the newly designed, reconstructed and existing facilities. This is a flexible method which can be used by large continuous facilities (for example petrochemical) but also by small discontinuous processes and independent devices.

The system carries out the registration of centres and workplaces in target organizations of its usage and the registration of industrial accidents. In addition to its primary functions, the system also supports the work with a simple text editor, e-mail and the access to a default internet web browser.

\section{User interface}

The work environment of this application was developed similarly to classical software applications of the Windows operating system. Dialog forms are accessed through main items of the system menu and the icons on the toolbar (Fig. 1).

Dialog forms contain bookmarks with text fields connected to data stored in database charts, set of icons for editing and moving through data records, filtering, sorting, deleting and adding data entries. The application contains a help which can be activated by pressing the F1 tab. Each chapter of help is interconnected with an active dialog form on the desktop. For quick orientation within the application's environment, an assistant describing the activity is activated by clicking the question mark icon.

\section{Application of the methods for risk identification and assessment}

The method of combined approach can be used for occupational safety assessment in a given workplace. This procedure integrates the methods of Catalogue sheets for the identification of risks and risk factors with the Scoring method.

Catalogue sheets represent a two-parameter record of causal dependency for a set category of risks. They contain information about given technical devices or segments of these devices. Catalogue worksheets are used from the stage of the design proposal of a system (operation) until its disposal. The main aim of a 


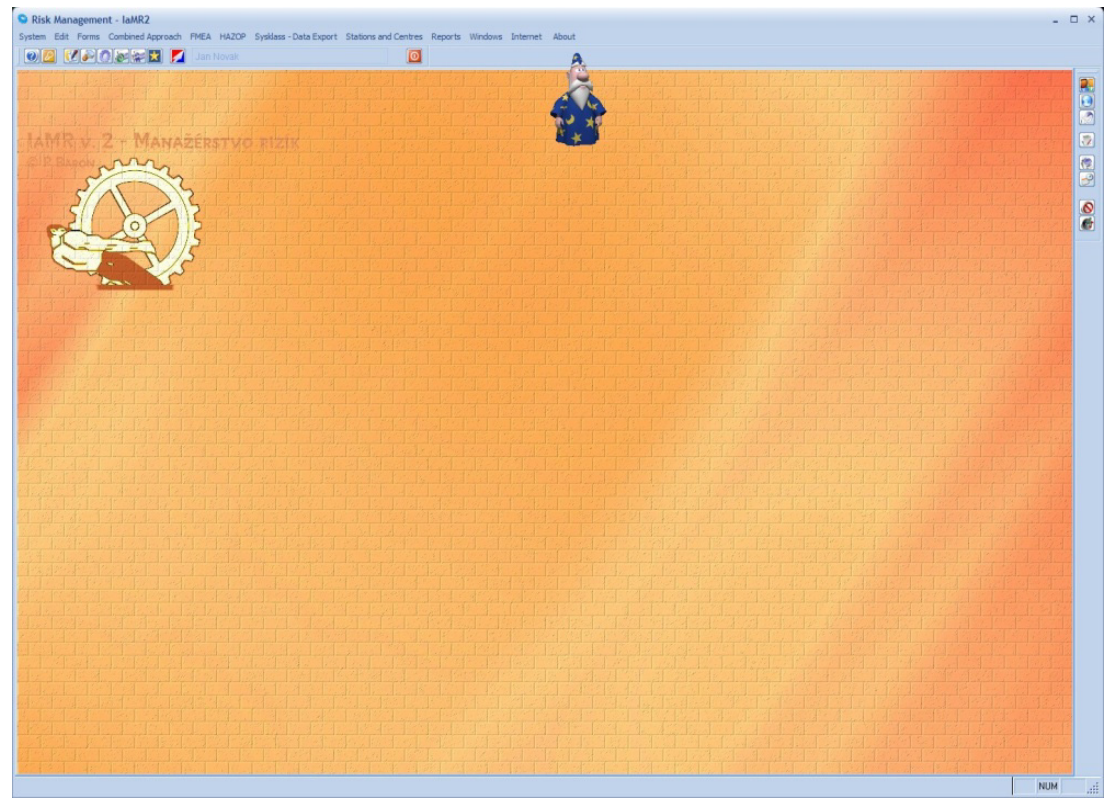

Figure 1: Interface of the computer application for the support, identification and assessment of risks and registration of industrial accident records.

catalogue sheet is quick recognition of danger in a specific operation. This means that continuous updating is necessary for the entire lifetime of the system. This method is simple to use, not requiring extensive theoretical knowledge, just enough practical knowledge of the system. When used for risks identification, it facilitates necessary interventions at the lower and mid-level risk level management [7].

The system processes the requested information about risk through fields placed on the tabs of sheets. The final version of the form is created by combining them with the data chart with relevant information about workplaces and with a table containing risk identification and risk factors. In the data can be filtered or sorted according to the users' requests (Fig. 2). The results are generated in the form of print outputs of risk register summary. The form used for calculating the risk score is activated with a position in the segments of technical device that have been selected in the catalogue sheet. There is also a feedback between both the dialog forms.

Scoring method is used for risk assessment in the phase of preliminary analyses as well as in phase of detailed analyses [7]. In order to achieve the most effective process of risk assessment it is advisable to assign exact value to a specific risk. Risk is therefore generally perceived as a function of at least two parameters - multiplicity or probability and consequence. 


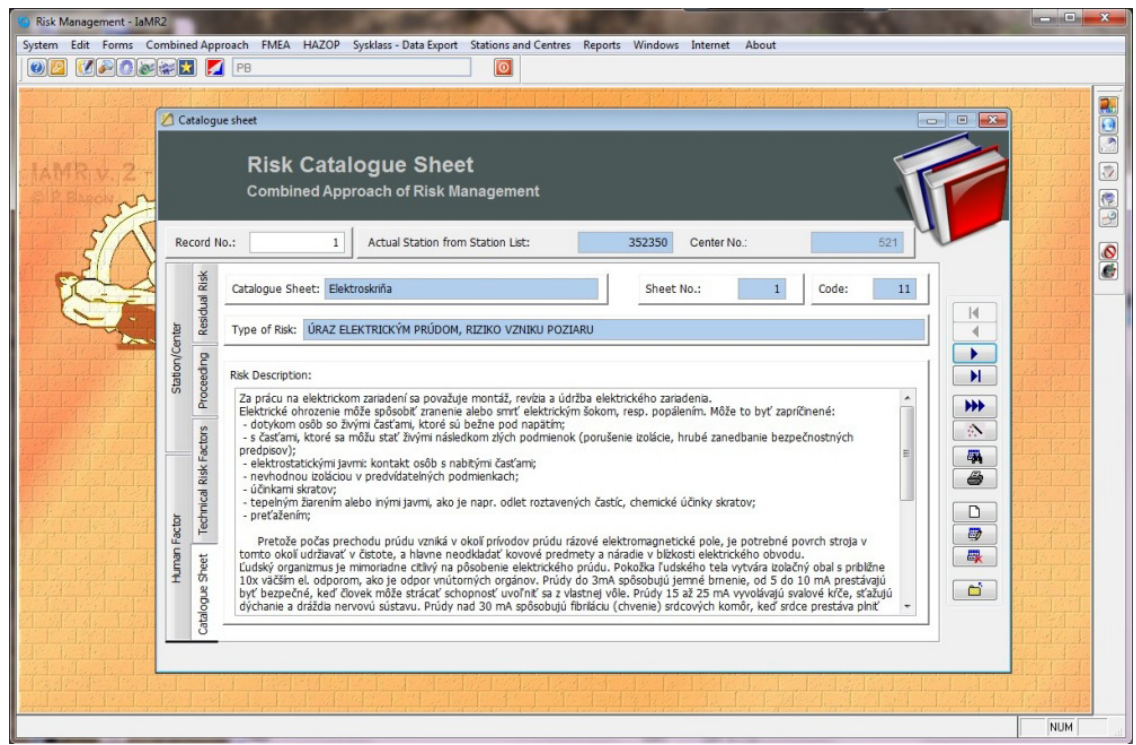

Figure 2: Catalogue sheet processing for risk assessment of functional segments of observed device.

The probability estimation is very often based on the statistical data related to injuries or on qualified estimates of failure rates.

The consequence depends on:

- scale of damage

- $\quad$ seriousness of damage

- financial loss

Assigning value to combinations of probability and consequence of adverse event levels creates a risk matrix. The risk score ranges from 1 to 20 points. The lower the score, the more urgent the realization of detailed risk analysis is. During the assessment of safety system it is necessary to analyze unacceptable conditions and to exclude the acceptable ones.

The application constructs the risk matrix by exact determination of probability and consequence of adverse event category from group of defined categories by selecting appropriate ratio button particularly for consequence and probability. After pushing the "Risk Calculation" button, the risk matrix is designed. This means the determination of risk score which is connected to its categorisation to categories ranging from Low risk to High risk. A unit responsible for correction is also defined and pushing the "Registration" button identifies the user currently logged into the system as the of risk assessor in the output summary (Fig. 3). 


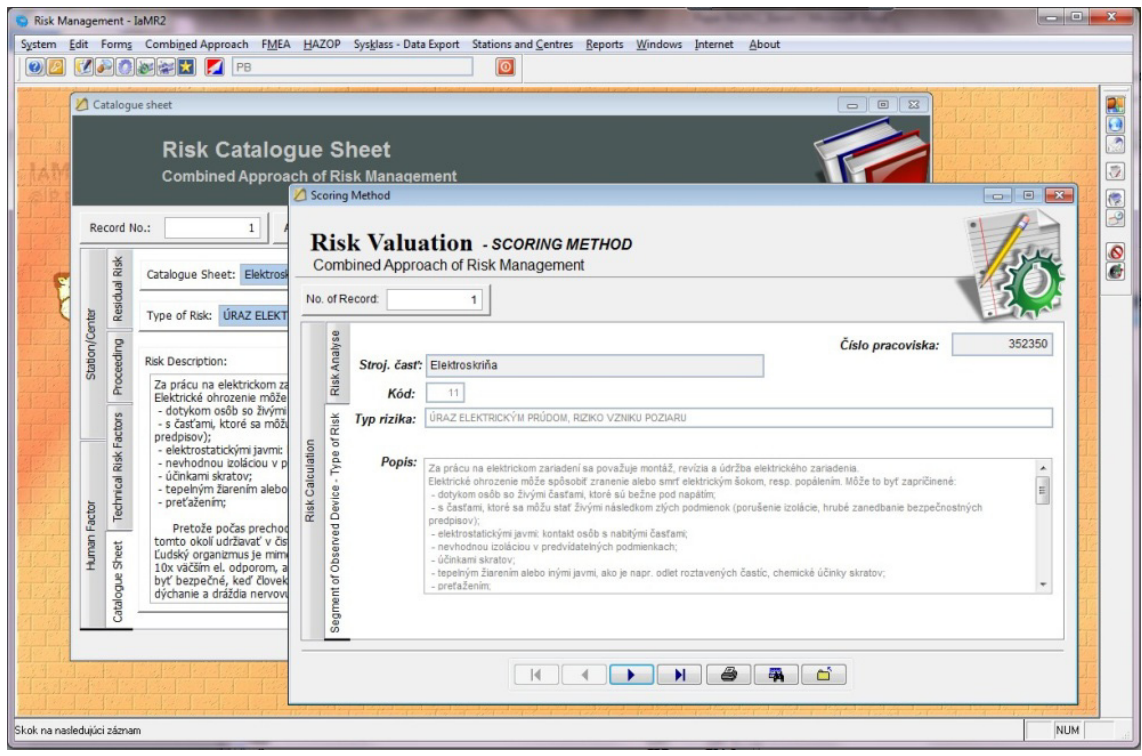

Figure 3: Calculation of risk using scoring method.

One of the most frequently used methods for risk consideration and assessment is definitely the FMEA method (Failure Mode and Effect Analysis). The development and usage of this method is connected with NASA's Apollo project of the mid-1960s. The main aim of this statistical method is to analyse the probable error occurrences and identify their consequences that might affect the product but also the production process and to propose correction steps for the elimination of the already existing or potential errors. FMEA is a method which allows for the identification of serious errors affecting the functionality of the product and process within the proposed application. Based on the failure characteristics of an element and functional structure of the element, it establishes the relationship between component failures and system, function failure operation restrictions and degradations of operability or compatibility of the system [7, 8]. This approach can follow the quality of construction of individual components but also to analyze the given process of production (Design FMEA - Process FMEA).

Our expert system applies the constructional FMEA, assuming the integration of the failure and risk identification of the newly proposed components and products with design changes of their production documentation carried out by the selected CAPP (Computer Aided Process Planning) system Sysklass. Using a block scheme, the reviewed design segment is divided into functional parts. For each design segment the expert system creates a data record proposal. In addition to the identification fields of the assessed segment, the analysis of the error occurrence possibility, its causes and impact on the particular segment are presented in the dialog form. At this point it is important to identify the type of error, its causes and possible impact. Conclusions are made based on the 
communication with the design and technological team members and employees involved in the production of the given component. Risk Priority Number, establishing the criticality of individual types of errors, is then calculated. Important part of this method is the proposal of corrective steps for the elimination of critical errors or limiting their occurrence and consequences. This action is followed by recalculation of risk number of the given part, after corrective actions have been applied - very often in form of design, technological changes or increasing of quality controls [9].

The risk number calculation form enables the reviewer to choose a coefficient from the list of coefficients of error occurrence probability, seriousness of the error and the probability of its detection. Each of the selected coefficients is accompanied by a brief characterisation that facilitates positive identification. If the calculated value of risk number falls within the range for which it is necessary to execute corrective actions, pushing the OK- risk number calculation button generates a range of proposed corrections (Fig. 4).

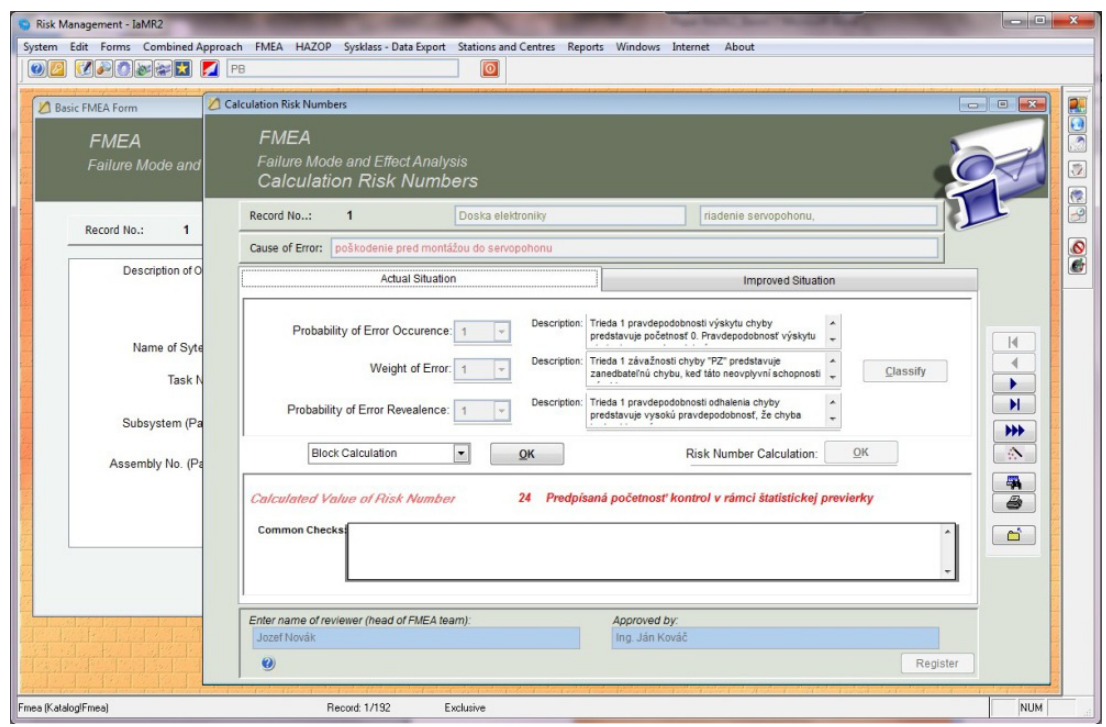

Figure 4: Dialog form for risk number calculation of a given segment.

The design of the print report complies with the requirements of the technical norm STN EN 60 812. This application of the FMEA method allows for the assessment and ensures failure free operation of products.

The last method of risk assessment which is supported by our expert system is the HAZOP method (Hazard Analysis and Operability Study). Its development is connected with a tragic industrial disaster at the petrochemical facility in Flixborough (Great Britain) in 1974. Even though risk identification is the main aim of this method, it is necessary to realize that operability issues should also be identified, since neglecting them might potentially lead to health, system or 


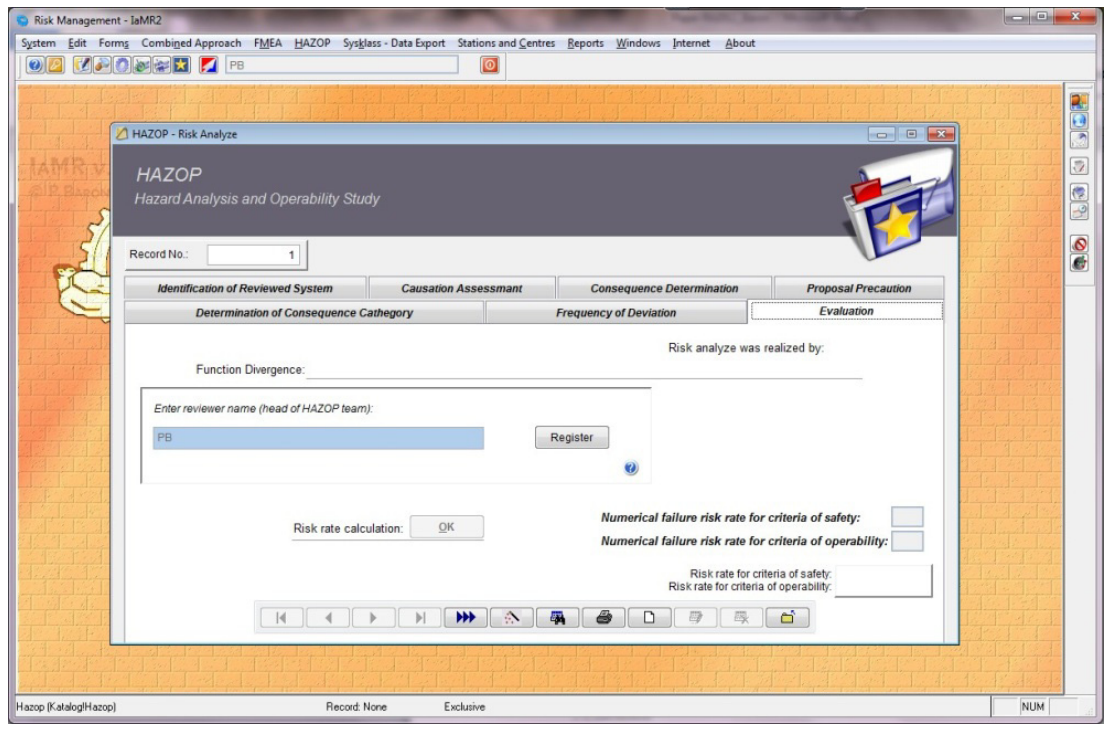

Figure 5: Application of HAZOP method in the expert system environment.

environment damage or to lower the profitability of the system. For the purposes of the study, the system is divided into logical functional subsystems, similarly to the FMEA method. Such division is always voluntary and its aim is the creation of simplest subgroups with a single specific purpose. A smaller team of experts is required for the assessment of the project (operation or system). Every partition and subsystem undergoes a complex assessment, using a set of keywords. These enable the members of the team to get familiar with the system quickly and consequently to identify probable deviations from the proposed conditions. It is also very important to define whether such conditions exist. If yes, it is inevitable to examine their consequences [10]. Through combination of keywords and defining the purposes of the device nearly all patterns which may create deviations are examined. This procedure identifies a set of theoretical deviations from the standard purpose. Each of them needs to be assessed, determining its causes and possible consequences.

In the form used for the HAZOP method, the category of consequence is assigned following the specification of the cause of the deviation in the function of the selected segment of the device that is being reviewed, for the criteria of safety and operability. The respective consequence, the description of which is available in an editable field named Characteristics, is selected from the pop-up menu. After pushing the Add Consequence Category button, the field of criterion consequences is filled with data used for the ultimate determination of risk related to the given deviation of function.

Similar approach is used for determining the frequency of deviation as a probability category. For example, selecting the 0,1 value means that observed the deviation falls within the range of 0,9 to 0,1 times per the observed period. The most commonly used period is 1 year. The tab Assessment determines the 
risk rate if the rates of consequences and probabilities have been set. The text field Reviewer contains the name of the user who is logged into the system. If the computing module is unlocked, it is possible to change it to the head of the assessment team. Pushing the OK button activates the calculation of the risk score (Fig. 5).

\section{Conclusion}

Computer-aided risk assessment opens new a view on occupational safety, health protection and technical device safety. It enables the automation of those procedures and modes that lead to the design and application of preventive measures that are necessary for a safe workplace. From a global perspective, it is necessary to take into consideration the following:

- $\quad$ every activity entails risk

- $\quad$ safety requires the acceptance of a certain level of risk

- the degree to which this risk is acceptable varies according to the level technical, social, cultural progress and scientific knowledge

- managing the risk means assessing it beyond what is required by law rather than merely following legal norms and their requirements

- risk can be managed by means of technical, organizational and educational measures

- risk assessment does not warrant absolute elimination of accidents or damages to the equipment of work environment. It is therefore important to prepare procedures for handling adverse situations

- residual risk cannot be regarded as acceptable

- all the employees and other persons potentially at risk must be fully informed about any potential threat, even if the probability of any adverse event is small

- $\quad$ risk must be manageable by those that may potentially create it at all stages of development and production

- the process of risk management must be systematic and form and integral part of employees' training and work organization

The above mentioned considerations lead to the development of an expert system processing a limited set of data through characteristic procedures. The system was gradually upgraded according to requirements that include the possibility of industrial accident registration. Every database for a specific type of risk can be exported into predefined forms of output reports or in the *.xls format. It also supports the generation of data archives and retrieval of data records from these files. The system also integrates the CAPP system Sysklass [11]. This tool can be activated directly from the expert system environment, so that the results of risk assessment of newly designed products can be directly incorporated into the production documentation. Such a technique represents a new approach in computer support of preproduction stages, commonly known as concurrent engineering. 
There are no exact rules for risk assessment. Individual steps for risk identification are delimitated by an algorithm but later often merged again in practice. Distinguishing for example between whether work with dangerous substances is a danger or treat might prove to be an unnecessary complication. What is important is to determine whether employees may or may not be in danger. If the assessment is made for a selected system (machine, activity or work environment) the main task is to identify conditions, characteristics and aspects which may possible possibly result in damage, accident or health hazard.

The expert system was designed in compliance with present national and European legislation which demands the application of assessment and risk management system at every stage of a technical system's lifetime, especially at the stage of:

- $\quad$ machine design and planning

- machine production

- machine operation and maintenance

- machine disassembly and disposal

Risk assessment of workplaces and technical systems is a never ending process. In the era of the complex informatization of society, the above described approach represents a fully functional tool for risk assessment $[12,13]$.

\section{Acknowledgements}

Ministry of Education, Science, Research and Sport of the SR supported this paper, contract VEGA no. 1/0013/11 and ITMS project no. 26220220125.

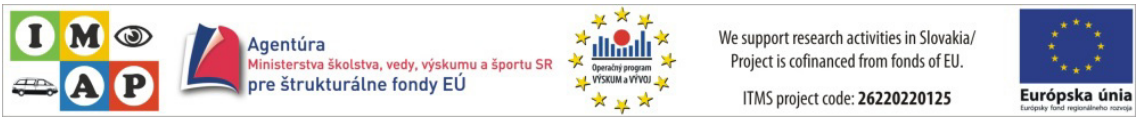

\section{References}

[1] Kandráč, J. - Skaraba, D.: Metodický postup na hodnotenie rizík nebezpečných prevádzok a štúdia o podnikoch $\mathrm{v}$ Slovenskej republike, http://www.lifeenv.gov.sk/minis/chem latky/prevencia/metodika/risk.htm

[2] Matija, R., Vasilko, K., Vojtko, I.: Zariadenie na generovanie plynného procesného média s ozónom úžitkový vzor č. 5707/ Rudolf Matija, Karol Vasilko, Imrich Vojtko - Banská Bystrica: ÚPV - 2011. - 4 s.

[3] Murčinko, J., Murčinková, Z.: Application of Monitoring System in Drying Section of Printing Machines, In: Proceedings in Manufacturing Systems. Vol. 6, no. 4 (2011), p. 227-232. - ISSN 2067-9238.

[4] Sadílek, M., Čep, R., Budak, I., Soković, M.: Aspects of using tool axis inclination angle, Strojniski Vestnik/Journal of Mechanical Engineering Volume 57, Issue 9, 2011, Pages 681-688, ISSN 0039-2480. 
[5] Svetlík, J., Demeč, P.: Mathematical modeling of machining by decomposition of lathe on modules, Metalurgija. Vol. 51, no. 2 (2012), p. 285-288. - ISSN 0543-5846.

[6] Assess-Risk - A Software for Risk and Consequences Analysis for Chemical and Petrochemical sites http://www.fluidyn.com/ Home_English/products/Acc_Risk.htm

[7] Sinay, J.: Riziká technických zariadení - manažérstvo rizika, TU Košice VSŽ Košice, OTA Košice, 1997, 212 s., ISBN 80-967783-0-7.

[8] STN IEC 60812 Metódy analýzy spol'ahlivosti systému. Postup analýzy spôsobov a dôsledkov porúch (FMEA), Slovenský ústav technickej normalizácie, 93 s., 2006, ISBN 2-8318-8425-X.

[9] STN IEC 60812 Metódy analýzy spol'ahlivosti systému. Postup analýzy spôsobov a dôsledkov porúch (FMEA).

[10] Lihou, M.: Hazard \& Operability Studies http://www.lihoutech.com index.html

[11] Kuric, I., Košturiak, J., Janáć, A., Peterka, J., Marcinčin, J.: Počitačom podporované systémy v strojárstve, EDIS - vydavatel'stvo ŽU, 2002, 351 s., ISBN 80-7100-948-2.

[12] Sinay, Juraj, Pačaiová, Hana - ORAVEC, Milan: Present state of machinery safety assessment. In: DAAAM: Annals of DAAAM for 2005 19-22nd October 2005, Opatija, Croatia. Viedeň: DAAAM International Vienna, 2005. s. 347-348. ISBN 3-901509-46-1.

[13] Tomašková, M., Kopas, M.: Firemen interventions at road traffic accidents, In: From Integrated Management Systems towards Generic Management Systems - Approaches from Slovakia and Germany: Kolloquien zum Qualitätsmanagement: Band 3/2009. - Aachen: Shaker Verlag, 2009 P. 109-112. - ISBN 978-3-8322-8508-1 - ISSN 1611-6267. 